\title{
Harbor seal foraging response to a seasonal resource pulse, spawning Pacific herring
}

\author{
Austen C. Thomas ${ }^{1,3, *}$, Monique M. Lance ${ }^{2}$, Steven J. Jeffries ${ }^{2}$, Benjamin G. Miner ${ }^{1}$, \\ Alejandro Acevedo-Gutiérrez ${ }^{1}$
}

\author{
${ }^{1}$ Western Washington University, Department of Biology, Bellingham, Washington 98225-9160, USA \\ ${ }^{2}$ Washington Department of Fish and Wildlife, Wildlife Science Program, Lakewood, Washington 98498, USA \\ ${ }^{3}$ University of British Columbia, Marine Mammal Research Unit, Vancouver, British Columbia V6T 1Z4, Canada
}

\begin{abstract}
Evidence suggests that Pacific harbor seals Phoca vitulina are likely to alter their foraging behavior in response to seasonal prey pulses. We hypothesized that spawning herring $\mathrm{Clu}$ pea pallasii aggregations are seasonally important prey for harbor seals, predicting that (1) harbor seal consumption of adult herring would peak during the spawning season, (2) harbor seals would seasonally change their foraging areas to take advantage of spawning herring aggregations, and (3) seal diving behavior would reflect the vertical distribution of herring during the spawning season. The predictions were tested using an analysis of harbor seal prey remains, GPS telemetry, and satellite-linked time/depth recorder data. Contrary to predictions, herring in harbor seal diet was comprised of $74 \%$ juveniles and $26 \%$ adults in the spawn season, versus $37 \%$ juveniles and $63 \%$ adults in the post-spawn season. Harbor seal use of documented herring areas was highest during the season when herring did not spawn, and seal diving behavior did not reflect the vertical distribution of herring. The lack of response by harbor seals to spawning herring pulses is likely explained by the low energy density of adult herring during the spawn season, and the availability of profitable alternative prey such as juvenile herring. This study highlights the influence of relative prey profitability on the foraging behavior of harbor seals, and may help to explain why predators do not always respond as predicted to resource pulses.
\end{abstract}

KEY WORDS: Phoca vitulina $\cdot$ Resource pulse $\cdot$ Utilization distribution $\cdot$ Diet $\cdot$ Diving $\cdot$ Marine predators Resale or republication not permitted without written consent of the publisher

\section{INTRODUCTION}

Ecologists are increasingly interested in how largemagnitude variations in resource availability influence ecological communities (Ostfeld \& Keesing 2000, Holt 2008, Nowlin et al. 2008, Yang et al. 2008). These events, termed resource pulses, are defined as dramatic increases in resource availability and are characterized by relatively high intensity, low frequency, and short overall duration (Yang et al. 2008). While most conceptual work on resource pulses has focused on terrestrial ecosystems, several recent studies have highlighted that resource pulses are common in aquatic ecosystems (Willson \& Womble 2006, Nowlin et al. 2008, Yang et al. 2010), such as the periodic upwelling of nutrient-rich water into the euphotic zone (Adams et al. 2000, Longhurst 2001), episodic blue mussel settlement eliciting an aggregative response by sea stars (Bologna et al. 2005), and large aggregations of spawning fish that provide an important seasonal energy input to consumers (Willson \& Halupka 1995).

Pacific herring Clupea pallasii spawning aggregations are an excellent example of a marine resource pulse (Willson \& Womble 2006), that has received less attention than spawning events of other fishes such as salmon (Helfield \& Naiman 2001, Naiman et al. 2002, Nowlin et al. 2008, Yang et al. 2010). Pacific herring typically forage in offshore feeding grounds during the summer months and then make seasonal 
shoreward migrations each winter to spawn (Haegele \& Schweigert 1985, Lassuy 1989). During the months when Pacific herring are spawning, at least 25 vertebrate species, excluding fish, forage in large numbers at herring spawning sites on adult herring and eggs (Willson \& Womble 2006, Anderson et al. 2009).

Interestingly, harbor seals Phoca vitulina are absent from the list of known predators that aggregate at herring spawning sites (Norcross et al. 2001, Willson \& Womble 2006). Harbor seals are highly mobile, generalist predators, and therefore well adapted to take advantage of pulsed prey resources (Rose \& Polis 1998, Ostfeld \& Keesing 2000). Herring are also common in the diet of harbor seals throughout much of their geographic range (Thompson et al. 1991, Olesiuk 1993, Andersen et al. 2007); sometimes occurring in over $80 \%$ of harbor seal scat samples (Lance \& Jeffries 2007). Most notably, Pacific harbor seal consumption of herring appears to peak during the season when herring are spawning in certain regions (Olesiuk 1993), and some seals have been observed covered in herring eggs during the spawning season (Grigg et al. 2009). Combined, this evidence strongly suggests that harbor seals are among the predators that respond to spawning herring pulses.

In this study, we tested the hypothesis that spawning herring aggregations are seasonally important prey for harbor seals in the Strait of Juan de Fuca. The objective was to measure the seasonal changes in harbor seal diet, foraging distribution, and diving behavior relative to spawning herring aggregations. We predicted that: (1) harbor seal consumption of adult herring would peak during the season when herring are spawning, (2) harbor seals would seasonally change their foraging areas to take advantage of spawning herring aggregations, and (3) seal diving behavior would reflect the vertical distribution of herring in the water column when herring were spawning. These predictions were tested using an analysis of harbor seal diet, foraging areas, and diving behavior.

\section{MATERIALS AND METHODS}

\section{Study location}

Protection Island $\left(48^{\circ} 07^{\prime} 40^{\prime} \mathrm{N}, 122^{\circ} 55^{\prime} 50^{\prime} \mathrm{W}\right)$ is a small National Wildlife Refuge located in the eastern Strait of Juan de Fuca, Washington, USA (Fig. 1). It is known for its extensive seabird colonies and ecologi- cally important marine habitat. We selected Protection Island for our study due to its proximity to important herring spawning areas (Stick \& Lindquist 2009) and its relative importance as a harbor seal haul-out site (Jeffries et al. 2000). Two sandy spits extending eastward and westward from the island are used by 1000 harbor seals during all tidal phases (Jeffries et al. 2000). Discovery Bay, situated $\sim 3.5 \mathrm{~km}$ south of Protection Island, is the spawning site of the Discovery Bay herring stock, which was once the second largest herring stock in Washington State but has experienced a dramatic decline in recent decades, possibly due to harbor seal predation (Stick 2005). To the west of Protection Island, 2 other small herring spawning grounds make up the Dungeness/Sequim Bay herring stock (Fig. 1). While these 2 stocks are the closest to Protection Island, all of Washington's inland spawning stocks were considered in the

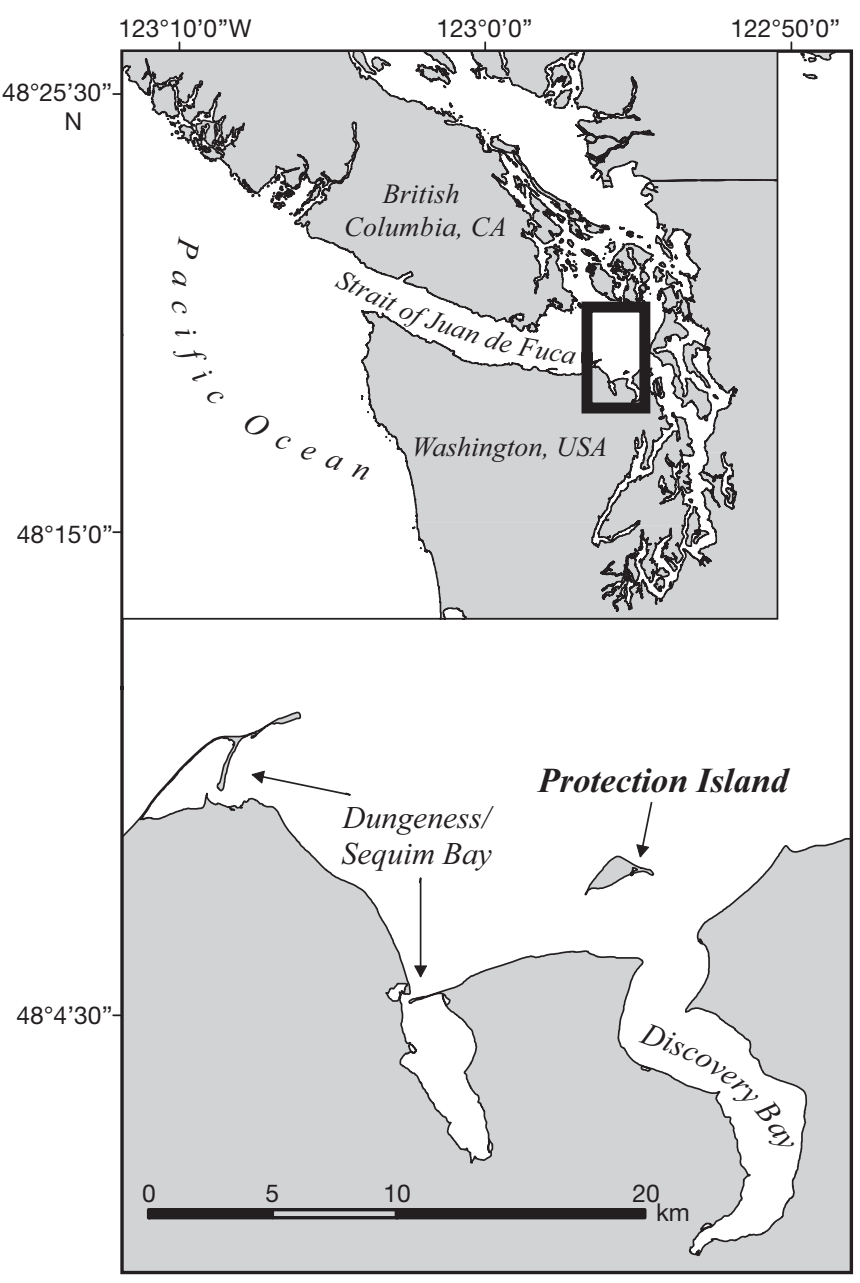

Fig. 1. Study location, Protection Island, Washington, USA, and nearby bays used by Pacific herring for spawning 
analyses because all stocks were within foraging distance $(<150 \mathrm{~km})$ of Protection Island harbor seals (Hardee 2008).

\section{Harbor seal diet}

To assess seasonal changes in herring consumption by harbor seals, harbor seal fecal samples (scats) were collected on a single day during each of 2 herring-related seasons in 2009: spawn (16 March) and post-spawn (22 July). Seasons were defined based on the local spawn timing (Stick 2005, Penttila 2007). Scats were collected on both island spits during daytime low tides with a target sample size of 60 scats for each collection period (Trites \& Joy 2005). Samples were collected in plastic Whirlpak bags and frozen until processing, after which they were washed using nested sieves (mesh size range: 2.0-0.5 mm) (Lance et al. 2001). All diagnostic prey hard parts were identified to the lowest possible taxon using a dissecting microscope, reference fish bones from Washington and Oregon, and published fish bone, otolith, and cephalopod beak keys (Kashiwada et al. 1979, Morrow 1979, Wolff 1982, Clarke 1986, Cannon 1987, Harvey et al. 2000, Lance et al. 2001). Otoliths were measured using an ocular micrometer and graded based on the observed erosion (Tollit et al. 2004). To avoid biases associated with highly eroded otoliths, only those graded good (no or minimal erosion) and fair (small amount of erosion) were measured and used for subsequent calculations.

The percent frequency of occurrence (FO) for harbor seal prey species in scats was used for comparisons between seasons (spawn vs. post-spawn). To account for differences in sample sizes among seasons, here we calculated the absolute FO for each prey species by simply dividing the number of occurrences for each species by the number of scats collected in the respective seasons (Wright 2010). Top prey species were identified as those with FO $\geq 25 \%$ during one of the 2 seasons (Luxa 2008). For statistical comparisons of prey occurrence in harbor seal diet between seasons, Pearson's chi-square tests were used to compare the occurrence of the top prey species and the occurrence of adult and juvenile herring between seasons (Womble \& Sigler 2006, Wright 2010).

To estimate the age and size classes of Pacific herring consumed by harbor seals, we used a 3-step calculation. First, we estimated the lengths of herring consumed based on the measured otolith lengths of a single subset (left or right otoliths) using a published species-specific regression equation (Harvey et al.
2000). Second, we applied grade-specific length correction factors ( $g$-LCFs) to the estimated herring lengths in order to correct for digestion erosion. The use of $\mathrm{g}$-LCFs is proven to dramatically improve size estimates of fish consumed by pinnipeds based on otoliths in scat (Tollit et al. 2004, Phillips \& Harvey 2009); however species-specific g-LCFs were not available for herring. We therefore used the difference between the published average length correction factor (a-LCF) for herring (Harvey 1989), and that of the closely related species Pacific sardine Sardinops sagax (Phillips \& Harvey 2009) to generate $\mathrm{g}$-LCFs for herring using the following equation for each otolith grade:

$g-\mathrm{LCF}_{\mathrm{h} i}=100 /\left[100-\% \mathrm{SLR}_{i} \times\left(\mathrm{a}-\mathrm{LCF}_{\mathrm{h}} / \mathrm{a}-\mathrm{LCF}_{\mathrm{s}}\right)\right]$

where $i$ represents the otolith grade ('good' or 'fair'), $\mathrm{g}-\mathrm{LCF}_{\mathrm{h}}$ is the calculated grade specific length correction factor for herring, \%SLR is the percent sardine length reduction for grade $i$ from Phillips \& Harvey (2009), and $\mathrm{a}-\mathrm{LCF}_{\mathrm{s}}$ and $\mathrm{a}-\mathrm{LCF}_{\mathrm{h}}$ are the average length correction factors for sardine and herring, respectively. Lastly, we calculated herring age classes consumed by harbor seals by comparing our estimated herring lengths to size-at-age data for Pacific herring in the region (Schweigert et al. 2009). Juvenile herring were differentiated from adults as those with an estimated age class < 3 (Hay 1985, Gustafson et al. 2006).

\section{Tag deployment and programming}

On 12 to 13 January 2009, 5 harbor seals were captured on Protection Island using the beach-seine method (Jeffries et al. 1993). All animals were weighed, measured and flipper tagged with a unique identification number. All seals (2 males, 3 females) received a combined satellite-linked time depth recorder (TDR) and Fastloc GPS receiver (model MK10AF, Wildlife Computers) that was attached to the pelage using 5-min epoxy. Instruments were placed on the dorsal midline on the animals such that the tag would be exposed to the air when the back of the seal reached the water surface. During 12 January to 3 July 2009, we received regular transmissions from all 5 tags via the ARGOS satellite network that contained compressed TDR and Fastloc GPS data. Messages were processed using the DAP Processor software provided by Wildlife Computers and the progress of the animals was monitored using the Satellite Tracking and Analysis Tool (Coyne \& Godley 2005). 
To conserve battery life, we limited the number of fast-GPS measurement attempts to a maximum of $4 \mathrm{~h}^{-1}$. The TDR sensor was set to sample every $10 \mathrm{~s}$ and record only dives $>2 \mathrm{~m}$ in depth or $>30 \mathrm{~s}$ in duration to avoid diving associated with surface behavior. The tags automatically summarized the TDR diving data of each animal into four 6-h time periods: morning (04:00-09:59 h), day (10:00-15:59 h), evening (16:00-21:59 h), and night (22:00-03:59 h) local time. Throughout the study, local sunrise always occurred in the morning period and sunset always occurred during the evening period. Transmitted maximum dive depth histograms tallied dives into twelve depth bins: $2-10,10-20,20-50,50-100,100-150,150-200$, 200-250, 250-300, 300-350, 350-400, 400-500, and $>500 \mathrm{~m}$. Only those depth bins that contained data for at least one animal were used in subsequent analyses.

To assess differences in foraging behavior between seasons, all transmitted GPS locations and TDR histograms were separated into 2 herring-related seasons of equal duration (84 d each): spawn (14 January7 April) and post-spawn (8 April-30 June) based on the spawn timing of local Pacific herring (Stick 2005, Penttila 2007). While it could be argued that differences in harbor seal movements and diving behavior between seasons may be attributed to seasonal changes other than foraging, harbor seals in the region do not appear to undergo any major life history changes (i.e. pupping, breeding, or molting) during the study period (Huber et al. 2001).

\section{Seal foraging areas}

To remove erroneous GPS locations from the data set, transmitted location data were initially filtered using the grpSpeedFilter function in the $\mathrm{R}$ package diveMove (Luque 2007), which applies the first stage of the filtering algorithm described in Austin et al. (2003). For this function we used the species-specific speed threshold of $2 \mathrm{~m} \mathrm{~s}^{-1}$ applied in previous harbor seal studies (Williams \& Kooyman 1985, Lesage et al. 1999). Because our interest was in the foraging distribution of harbor seals, we also eliminated locations associated with haul-out behavior. Thompson et al. (1998) defined harbor seal foraging locations as any identified location $>2 \mathrm{~km}$ from a haul-out site. However, based upon our observations of foraging seals around Protection Island and the abundance of high quality fish habitat $<2 \mathrm{~km}$ of the island, we concluded that a $2 \mathrm{~km}$ buffer would be far too conservative and therefore chose to eliminate locations
$<0.5 \mathrm{~km}$ from the documented haul-out sites (Jeffries et al. 2000). It should be noted that the buffered regions did not include any documented herring areas.

To address the questions of seal space use in this study, we adapted spatial modeling techniques commonly used in home range studies in order to identify animal high usage areas (Worton 1995). Using the GPS points defined as foraging locations, 2 foraging utilization distributions (UDs) were calculated for each seal and for each herring-related season. To quantify changes in space use between seasons, the first UD calculated was a fixed kernel density estimate which is often cited as the preferred method for identifying an animal's home range or high use areas (Powell et al. 2000). The resultant UDs were later used in the calculation of overlap indices (Fieberg \& Kochanny 2005). For the fixed kernel estimates we used the ad-hoc method of bandwidth selection because the least square cross validation function failed to minimize (Worton 1995, Calenge 2006). While fixed kernel UDs are useful for quantifying UD similarity, they are less effective for describing actual areas used by animals in close proximity to hard boundaries such as coastlines (Getz et al. 2007). To better estimate the sizes and locations of seal foraging areas, the second UD calculated was an adaptive local convex hull (a-LoCoH) (Getz et al. 2007, Huck et al. 2008). Local convex hull UDs use a non-parametric kernel method based on a generalization of the minimum convex polygon (MCP), and perform well around coastline boundaries. The resulting $95 \%$ UD contour was used to describe the overall foraging area used by each seal, and the $50 \%$ contour for the core foraging area (Ostfeld 1986, Hyrenbach 2002, Hardee 2008).

Using the fixed kernel density UD estimates, we calculated an index of UD overlap to assess whether seals used different foraging areas between the spawn and post-spawn seasons. An extensive review of UD overlap indices concluded that the utilization distribution overlap index (UDOI) is the most appropriate for analyses of space-use sharing (Fieberg \& Kochanny 2005). In general, UDOI values $<1$ indicate less overlap than would be expected from overlapping uniform distributions, whereas values $>1$ indicate greater UD overlap than would be expected from overlapping uniform distributions. To statistically compare UDs between seasons, we created a set of reference values for UDOI by generating a null distribution of overlap indices from 10000 simulated, completely overlapping, random, uniform distributions. Using the simulated overlaps, we calculated a 
p-value for each seal's overlap statistic, i.e. the probability of obtaining a value less than or equal to the observed overlap value from the null distribution.

Finally, we quantified harbor seal use of herring habitat by calculating the percentage of each seal's foraging area (described by the a-LoCoH UDs) that overlapped with 2 publically available herring datasets: (1) the documented locations where herring aggregate prior to spawning (holding areas), and (2) documented locations where herring regularly deposit eggs (spawning areas) (Stick 2005, Stick \& Lindquist 2009). While the timing of herring spawn is quite consistent between years, there is moderate between-year variability in the locations of herring holding areas (K.C. Stick, Washington Department of Fish and Wildlife, pers. comm.). Thus, caution should be exercised in the interpretation of the UD/herring area overlap calculations.

\section{Seal diving behavior}

We calculated 3 diving variables from the maximum dive-depth histograms to describe seal diving behavior during the four 6 -h periods. Any histograms that contained $<10$ dives per histogram were excluded from the analysis to prevent small sample size bias (Hastings et al. 2004).

\section{Dive depth focus}

The degree to which harbor seals focused their diving to a single depth bin was assessed by calculating the dive depth focus (F) within each histogram (Frost et al. 2001, Hastings et al. 2004):

$$
F=\sum\left\{\left[\mathrm{n}_{i}\left(\mathrm{n}_{i}-1\right)\right] /[\mathrm{N}(\mathrm{N}-1)]\right\}
$$

with $n$ being the number of dives per meter in bin $i$ and $\mathrm{N}$ being the total number of dives in the histogram (Hastings et al. 2004). Values of dive depth focus ranged from 1.0 (high focus) to 0.167 (low focus) with values $>0.5$ indicating that most dives within the histogram were to a single depth bin.

\section{Modal dive depth}

Previous studies of harbor seal diving behavior using satellite-linked data loggers found that modes are strongly representative of seal diving behavior (Frost et al. 2001, Hastings et al. 2004). Thus, harbor seal use of the water column was summarized by cal- culating the modal dive depth, i.e. the depth bin with the highest number of dives per meter within a histogram. In the rare case when a mode could not be identified because 2 depth bins had equal dives per meter, that histogram was removed from subsequent analyses (Hastings et al. 2004). To perform statistical analyses on the modal dive depth, we rescaled the depth bins to integers $(1-12)$ from the shallowest to the deepest bin, e.g. $1=(2-10 \mathrm{~m}), 2=(10-20 \mathrm{~m}), 3=$ $(20-50 \mathrm{~m}), 4=(50-100 \mathrm{~m})$, etc. Units for modal dive depth figures therefore correspond with the rescaled depth bin integers (Hastings et al. 2004).

\section{Diving frequency}

We used dive frequency (i.e. the number of dives per hour during each 6-h histogram) as a metric of overall foraging effort. As previously stated, since harbor seals in the region do not undergo major life history changes between the 2 seasons compared in this study, we believe that changes in diving frequency between the herring-related seasons are very likely attributed to changes in foraging behavior.

We used linear mixed effects models (LME) to test the effects of season (spawn, post-spawn) and period (morning, day, evening, night) on the 3 dive parameters using the R package lme4 (Bates \& Maechler 2009). Of the 2 fixed effects, period was nested within season, and both were nested within the random effect of seal. For each dive parameter we compared the fit of models that contained an interaction between the fixed effects and models containing each separate main effect. Model fit was compared using Akaike's Information Criterion (Akaike 1974).

\section{RESULTS}

\section{Harbor seal diet}

We collected 126 harbor seal scats from Protection Island during the 2 seasons (spawn: $\mathrm{n}=61$, postspawn: $n=65$ ) (Table 1). The average number of species per scat was $2.5 \pm 1.4 \mathrm{SD}$ during the spawn season, and $2.2 \pm 1.3$ during the post-spawn season; with 8 being the maximum number of prey species identified in a single scat. Only 1 scat collected during the post-spawn season contained no identifiable remains. Overall harbor seal diet included at least 21 species from 16 families. In both seasons the top prey species were Pacific herring, Walleye pollock Thera- 
gra chalcogramma, and Pacific sand lance Ammodytes hexapteras; however the importance of each top prey species varied between seasons (Table 1). In the spawn season the dominant prey species was Walleye pollock $(\mathrm{FO}=62 \%)$ followed by Pacific herring $(\mathrm{FO}=43 \%)$ and Pacific sand lance $(\mathrm{FO}=28 \%)$. The opposite trend was observed in the post-spawn season, with the most important prey species being Pacific sand lance $(\mathrm{FO}=42 \%)$ followed by Pacific herring $(\mathrm{FO}=40 \%)$ and Walleye pollock $(\mathrm{FO}=25 \%)$. Only a minor difference (3\% FO) in harbor seal herring consumption was observed between the spawn and post-spawn seasons. Of the top prey species occurrences, only Walleye Pollock differed significantly between the 2 seasons $\left(\chi^{2}=16.74, \mathrm{p}<0.001\right)$; whereas the occurrence of herring $\left(\chi^{2}=0.01, \mathrm{p}=\right.$ $0.91)$ and sand lance $\left(\chi^{2}=2.02, p=0.16\right)$ did not differ between seasons.
A combined total of 230 herring otoliths were recovered from harbor seal scats (spawn: $\mathrm{n}=109$, post-spawn: $n=121$ ). Based on the species-specific regression equation and correction factors, the average corrected herring length $(14.9 \mathrm{~cm})$ was $28 \%$ larger than the average uncorrected herring length $(11.2 \mathrm{~cm})$. There was a remarkable difference in the estimated age classes of herring consumed between the 2 seasons (Fig. 2). During the spawn season, herring in harbor seal diet comprised $74 \%$ juveniles (estimated age class $<3$ ) and $26 \%$ adults, versus the post-spawn season in which $37 \%$ were juveniles and $63 \%$ were adults $\left(\chi^{2}=15.79, p<0.001\right)$. Most $(91 \%)$ of the juvenile herring consumed during the spawn season were $<2 \mathrm{yr}$ in age. Of the adult herring consumed during the spawn season, the majority were age $>7 \mathrm{yr}$; whereas seals consumed a variety of adult herring age classes during the post-spawn season.

Table 1. Phoca vitulina. Number of occurrences and percent frequency of occurrence (FO) of prey species in harbor seal scats collected on Protection Island (WA, USA) during the herring spawn and post-spawn seasons

\begin{tabular}{|c|c|c|c|c|c|c|c|}
\hline \multirow{2}{*}{ Phylum } & \multirow{2}{*}{ Family } & \multirow{2}{*}{ Group or species } & \multirow{2}{*}{ Common name } & \multicolumn{2}{|c|}{ Spawn $(\mathrm{n}=61)$} & \multicolumn{2}{|c|}{ Post-spawn $(\mathrm{n}=65)$} \\
\hline & & & & No. & $\mathrm{FO}(\%)$ & No. & $\mathrm{FO}(\%)$ \\
\hline \multicolumn{8}{|l|}{ Chordata } \\
\hline & \multirow[t]{5}{*}{ Gadidae } & & & 50 & 82 & 24 & 37 \\
\hline & & Unidentified gadids & Codfishes & 9 & 15 & 6 & 9 \\
\hline & & Theragra chalcogramma & Walleye pollock & 38 & 62 & 16 & 25 \\
\hline & & Merluccius productus & Pacific hake & 0 & 0 & 1 & 2 \\
\hline & & Gadus macrocephalus & Pacific cod & 3 & 5 & 1 & 2 \\
\hline & \multirow[t]{4}{*}{ Clupeidae } & & & 36 & 59 & 42 & 65 \\
\hline & & Unidentified clupeids & Herrings & 9 & 15 & 16 & 25 \\
\hline & & Clupea pallasii & Pacific herring & 26 & 43 & 26 & 40 \\
\hline & & Alosa sapidissima & American shad & 1 & 1.6 & 0 & 0 \\
\hline & \multirow[t]{3}{*}{ Salmonidae } & & & 12 & 20 & 21 & 32 \\
\hline & & Unidentified salmonids & Salmon & 11 & 18 & 21 & 32 \\
\hline & & Oncorhynchus tshawytscha & Chinook salmon & 1 & 16 & 0 & 0 \\
\hline & \multirow[t]{3}{*}{ Cottidae } & & & 5 & 8 & 2 & 3 \\
\hline & & Unidentified cottids & Sculpins & 2 & 3 & 1 & 2 \\
\hline & & Leptocottus armatus & Staghorn sculpin & 3 & 5 & 1 & 2 \\
\hline & Ammodytidae & Ammodytes hexapteras & Pacific sand lance & 17 & 28 & 27 & 42 \\
\hline & Embiotocidae & Cymatogaster aggregata & Shiner perch & 11 & 18 & 2 & 3 \\
\hline & Engraulidae & Engraulis mordax & Northern anchovy & 2 & 3 & 1 & 2 \\
\hline & Pleuronectidae & Unidentified pleuronectids & Righteye flounders & 2 & 3 & 5 & 8 \\
\hline & Liparidae & Unidentified liparidids & Snailfishes & 1 & 2 & 0 & 0 \\
\hline & Rajidae & Unidentified rajids & Skates & 1 & 2 & 5 & 8 \\
\hline & Osmeridae & Unidentified osmerids & Smelts & 1 & 2 & 0 & 0 \\
\hline & Scorpaenidae & Unidentified scorpaenids & Rockfishes & 0 & 0 & 1 & 2 \\
\hline & Zoarcidae & Unidentified zoarcids & Eelpouts & 2 & 3 & 2 & 3 \\
\hline & Pholidae & Unidentified pholids & Gunnels & 1 & 2 & 0 & 0 \\
\hline & & Unidentified fish spp. & & 1 & 2 & 5 & 8 \\
\hline & & Unidentifiable fish spp. & & 3 & 5 & 0 & 0 \\
\hline Mollusca & Octopodidae & Octopus rubescens & Pacific red octopus & 3 & 5 & 4 & 6 \\
\hline & Loliginidae & Loligo opalescens & Market squid & 2 & 3 & 1 & 2 \\
\hline Arthropoda & & Unidentifiable crustaceans & & 2 & 3 & 1 & 2 \\
\hline
\end{tabular}




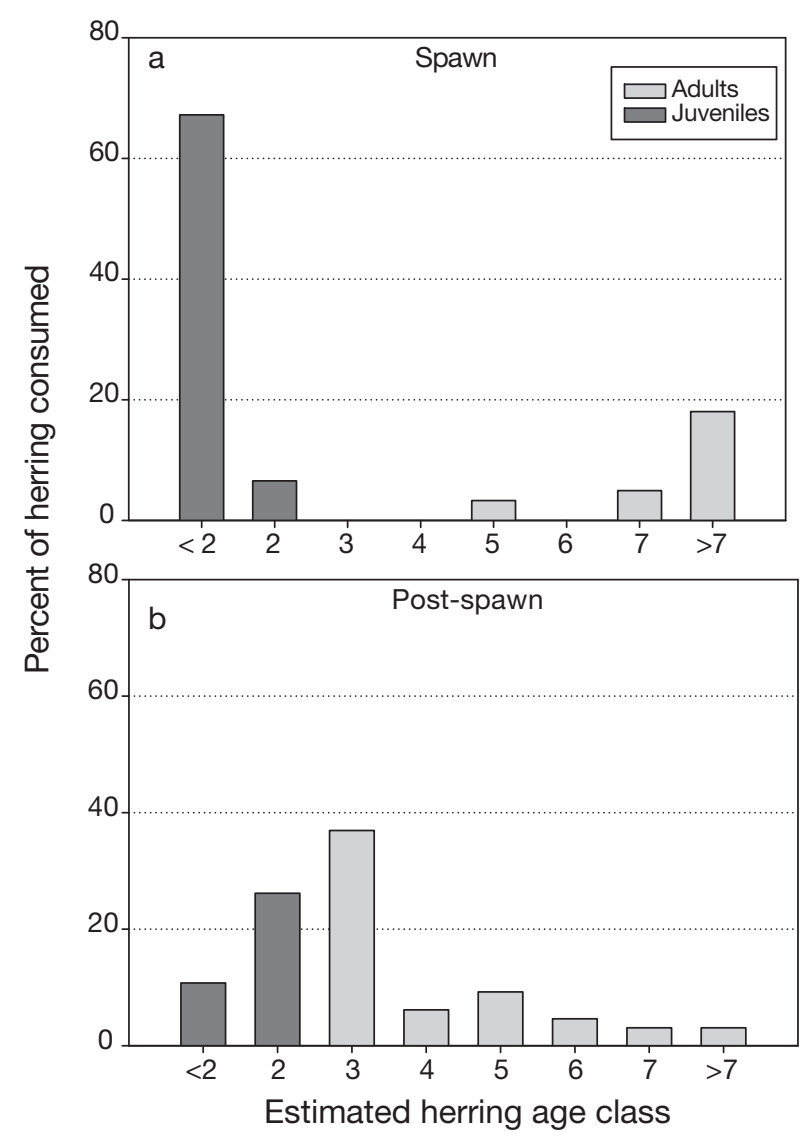

Fig. 2. Phoca vitulina. Distribution of estimated age classes of herring consumed by harbor seals during (a) spawn and (b) post-spawn seasons. Dark grey bars indicate herring estimated to be juveniles and light grey bars indicate adults

\section{Seal foraging areas}

All tags performed well during the study period with an average of $998 \pm 229$ (SD) GPS locations per seal (range: 840-1397) or approximately 6 locations per day. Filtering steps removed $1.5 \%$ of locations, and an additional $32 \%$ of locations were identified as haul-out behavior and removed before calculation of the foraging utilization distributions (Fig. 3).

According to the UDOI index of UD overlap, 3 of the 5 seals showed significantly less UD overlap between seasons than would be expected from completely overlapping uniform distributions at both the 95 and $50 \%$ contour levels, indicating that they switched foraging areas between seasons (Table 2). However, 2 of those 3 seals that were identified as having changed their foraging areas between the spawn and postspawn seasons exhibited only minor foraging area differences (Fig. 3, seals F3 and M1). Only one of the 5 seals foraged in a different region of the Strait of Juan de Fuca between seasons (Fig. 3, seal F1).
Table 2. Phoca vitulina. Utilization distribution overlap index (UDOI) between seasons (spawn/post-spawn) for each seal's $95 \%$ and $50 \%$ conditional utilization distributions. p-values represent the probability of obtaining an overlap value less than or equal to the observed overlap value from a null distribution of 10000 completely overlapping uniform distributions. ${ }^{*}$ indicates significant $\mathrm{p}$-value

\begin{tabular}{|lcccc|}
\hline Seal ID & UDOI 95 & $\mathrm{p}$ & UDOI 50 & $\mathrm{p}$ \\
\hline F1 & 0.812 & $<0.001^{*}$ & 0.099 & $0.045^{*}$ \\
F2 & 1.183 & $1.000^{*}$ & 0.151 & 0.711 \\
F3 & 0.892 & $<0.001^{*}$ & 0.014 & $<0.001^{*}$ \\
M1 & 0.929 & $<0.001^{*}$ & 0.043 & $<0.001^{*}$ \\
M2 & 1.185 & 1.000 & 0.104 & 0.071 \\
\hline
\end{tabular}

Four seals had overall foraging areas that overlapped with documented herring holding areas during 1 of the 2 seasons (Table 3, Fig. 3). For all of the animals that did use the herring holding areas, the proportion of their overall foraging area that overlapped with herring holding areas was greater during the post-spawn season (29\%) than it was during the spawn season (15\%). The same trend was observed for the portions of seal core areas that overlapped with herring holding areas (spawn: $5 \%$, postspawn: $23 \%$ ). Four of the 5 tagged seals did not forage in documented herring spawning sites at all. Only 1 animal foraged in herring spawning areas (F3), and the proportion of its overall foraging area that overlapped with those areas was small (Table 3, seal F3 in Fig. 3).

\section{Seal diving behavior}

The average number of histograms per seal was $220 \pm 33$ SD for the study period, after removing dive depth histograms with $<10$ dives. Average values for the diving variables were $0.60 \pm 0.08$ for dive depth focus (range from 0.167, indicating an even dive distribution across all depth bins, to 1.0 indicating all dives were to a single depth bin), $2.1 \pm 0.61$ for modal dive depth (i.e. the rescaled depth bin value), and $5.1 \pm 0.31$ dives $\mathrm{h}^{-1}$ for diving frequency.

Based on AIC values (Table 4), the best model fit for the dive depth focus variable included an interaction between season and time of day (Fig. 4a). In the spawn season, diving focus was greatest during the day but only slightly higher than the other 3 time periods. The most dramatic difference in dive depth focus occurred during the post-spawn season, in which diving focus was much greater during the night than any other time period. The best model for the modal dive depth variable contained only the 

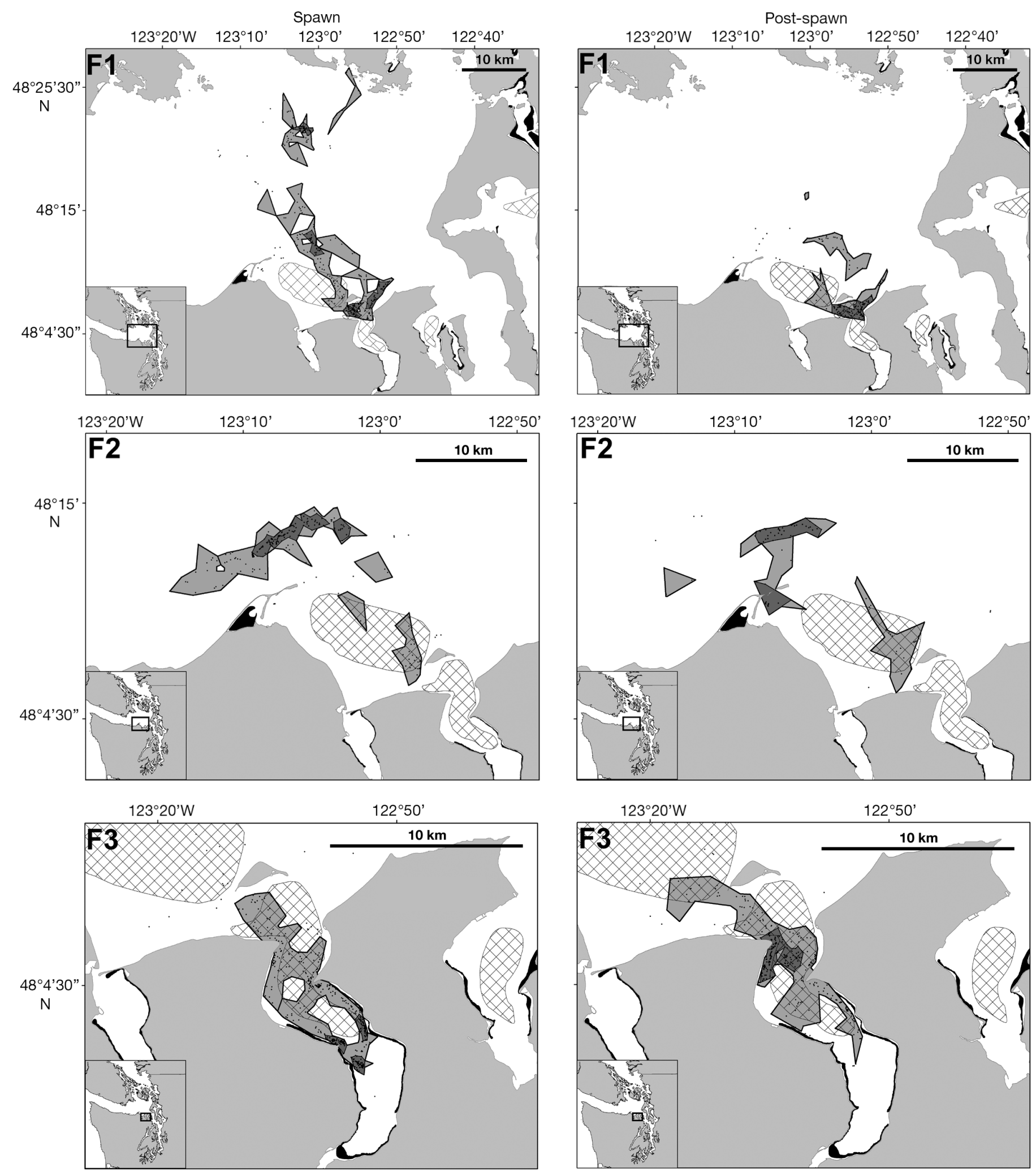

Fig. 3. (Above and facing page.) Phoca vitulina. Foraging areas of GPS-tagged harbor seals during the spawn (left) and postspawn (right) seasons, showing (small dots, •) GPS locations, ( $\square$ ) overall foraging areas (95\% a-LoCoH), ( $\square$ ) core foraging areas $(50 \%$ a-LoCoH $),\left(\square^{7}\right)$ herring holding areas, and $(\square)$ herring spawning areas. Seal ID and sex $(F=$ female, $M=$ male) are indicated in the upper left of each panel. Herring data provided by the Washington Department of Fish and Wildlife. a-LoCoH: adaptive local convex hull 

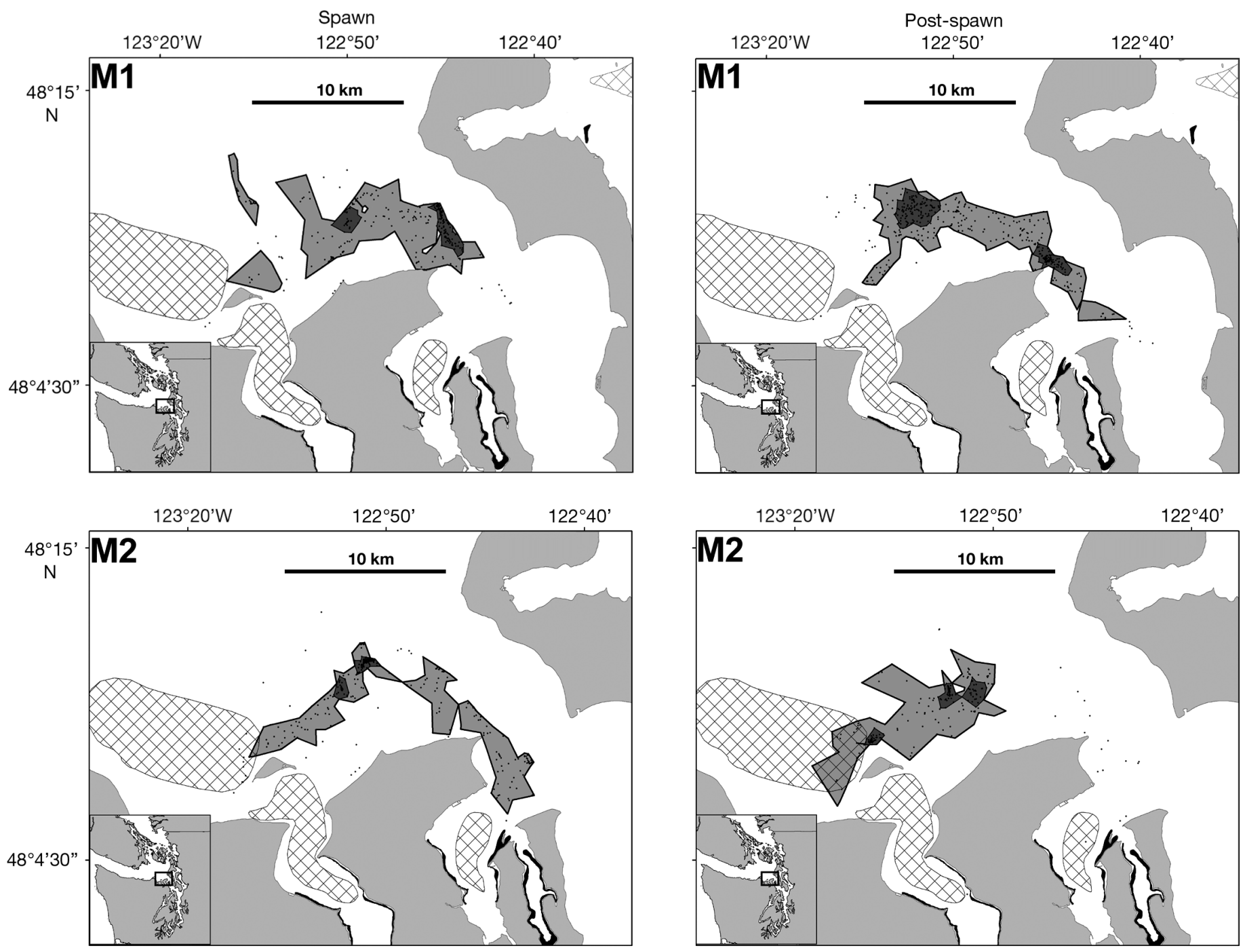

Fig. 3 (continued)

random factor of individual seal (Fig. 4b). Lastly, variation in diving frequency was best described by the effect of season, indicated by a proportionally large difference in diving frequency between the spawn and post-spawn seasons (Fig. 4c). Harbor seals dove on average 1.1 dives $\mathrm{h}^{-1}$ fewer (20\% change) during the spawn season than they did during the postspawn season $\left(\right.$ spawn $=4.43 \pm 0.35$ dives $\mathrm{h}^{-1}$, postspawn $=5.53 \pm 0.53$ dives $\left.h^{-1}\right)$.

\section{DISCUSSION}

\section{Harbor seal diet}

We detected 2 major differences in harbor seal diet between the spawn and post-spawn seasons. The first was a shift from a diet dominated by Walleye pollock during the spawn season to a diet that included a higher occurrence of Pacific sand lance and a lower occurrence of pollock during the postspawn season (Table 1). The second major change was a shift from eating almost entirely juvenile herring in the spawn season to eating mostly adult herring in the post-spawn season (Fig. 2)-although there was very little difference in the overall percent FO of herring between seasons. These observations are counter to our predictions that herring in harbor seal diet would peak during the spawn season, and that the herring consumed by harbor seals during the spawn season would primarily be spawning adults.

Two explanations could account for why Protection Island harbor seals did not consume many adult herring during the spawn season. The first and most 
Table 3. Phoca vitulina. Percentage of individual harbor seal foraging areas that overlapped with documented herring spawning and holding areas during the 2 herring seasons: spawn (spn), and post-spawn (post-spn). The percentage overlap was calculated for the core foraging areas (core area) and the overall foraging areas (overall area), based on the $50 \%$ and $95 \%$ a-LoCoH contours, respectively

\begin{tabular}{|lcccccccc|}
\hline Seal ID & \multicolumn{2}{c}{$\begin{array}{c}\text { Holding areas (\% overlap) } \\
\text { Core area } \\
\text { Spn Post-spn }\end{array}$} & $\begin{array}{c}\text { Spawning areas (\% overlap) } \\
\text { Overall area }\end{array}$ & \multicolumn{2}{c|}{$\begin{array}{c}\text { Core area } \\
\text { Overall area }\end{array}$} \\
\hline F1 & 17.0 & 57.8 & 13.6 & 34.1 & 0 & 0 & 0 & 0 \\
F2 & 0 & 0 & 16.5 & 27.5 & 0 & 0 & 0 & 0 \\
F3 & 10.3 & 58.7 & 46.0 & 60.8 & 2.6 & 0 & 0.6 & 0.5 \\
M1 & 0 & 0 & 0 & 0 & 0 & 0 & 0 & 0 \\
M2 & 0 & 0.4 & 0.9 & 20.9 & 0 & 0 & 0 & 0 \\
\hline
\end{tabular}

Table 4. Phoca vitulina. Linear mixed effects model results for the 3 dive variables. AIC: Akaike's Information Criterion

\begin{tabular}{|lrccc|}
\hline Model & df & AIC & $\Delta$ AIC & logLik \\
\hline Dive depth focus & & & & \\
Season $\times$ Period & 12 & -50.398 & 0.000 & 37.199 \\
Intercepts & 5 & -48.958 & 1.440 & 29.479 \\
Season & 6 & -47.799 & 2.599 & 29.900 \\
Season + Period & 9 & -47.515 & 2.883 & 32.758 \\
Modal dive depth & & & & \\
Intercepts & 5 & 3521.200 & 0.000 & -1755.600 \\
Season & 6 & 3521.300 & 0.100 & -1754.600 \\
Season + Period & 9 & 3524.800 & 3.600 & -1753.400 \\
Season $\times$ Period & 12 & 3528.900 & 7.700 & -1752.500 \\
Diving frequency & & & & \\
Season & 6 & 5396.600 & 0.000 & -2692.300 \\
Season + Period & 9 & 5397.200 & 0.600 & -2689.600 \\
Season $\times$ Period & 12 & 5398.300 & 1.700 & -2687.200 \\
Intercepts & 5 & 5403.800 & 7.200 & -2696.900 \\
\hline
\end{tabular}

likely explanation is that foraging on spawning herring is less profitable for harbor seals during the spawn season than foraging on juvenile herring or pollock. When herring migrate into the inshore waters to spawn, they cease foraging and largely rely on stored energy for gamete production and bodily maintenance (Paul et al. 1998). This behavior leads to a large decrease in herring energy density during the spawn season, equating to a reduction of $\sim 40 \%$ of their total somatic energy content (Paul et al. 1998). Juvenile herring however are only slightly less energy dense than adults during the spawn season, but likely require substantially less handling time and are regionally abundant in the spawn season (Lassuy 1989, Therriault et al. 2009). Given that handling times increase rapidly with prey size, some authors have suggested that small prey are retained in the diets of large predators because they are actually more profitable for predators when the energetic costs of prey acquisition are considered (Scharf et al. 2000). Thus, foraging on juvenile herring by harbor seals during the spawn season may be explained by the relative capturability of juveniles and the large proportional decrease in adult herring energy density. This finding implies that seasonal changes in the pulsed prey energy density and the availability of profitable alternate prey may both affect the likelihood that a predator will respond to the prey pulse.

Regional declines in herring spawner biomass offer a less likely explanation for why harbor seals primarily consumed juvenile herring during the spawn season. In the early 1980s, the Discovery Bay spawning population of Pacific herring was exceptionally large, but it has since undergone a sustained decline (Stick 2005, Gustafson et al. 2006, Stick \& Lindquist 2009). Despite the fact that herring still spawn in those areas in appreciable numbers, it is possible that the magnitude of the prey pulse in Discovery Bay may no longer be sufficient to elicit a response from harbor seals (Ostfeld \& Keesing 2000, Nowlin et al. 2008, Yang et al. 2008, 2010). However, if harbor seals only respond to exceptionally large magnitude spawning herring aggregations, then one would expect Protection Island harbor seals to have consumed a large proportion of herring during the spawn season when Strait of Juan de Fuca herring were historically abundant. Interestingly, historical harbor seal diet data from Protection Island in 1981 indicate that harbor seals consumed more herring during the summer ( $55 \%$ FO) than they did during the winter (29\% FO) when herring were spawning (Everitt et al. 1981). At that time, spawning herring biomass in the Strait of Juan de Fuca was $~ 10$ times larger than it is currently (Gustafson et al. 2006). Even more compelling is the fact that harbor seals on the Canadian side of the Strait of Juan de Fuca consumed largely juvenile herring in the spring during the 1980s (Olesiuk et al. 1990). The same study did not note high levels of juvenile herring consumption by harbor seals in the Northern Canadian waters, where herring consumption was also high in the spawn season. Combined, this information suggests that harbor seals in the Strait of Juan de Fuca prefer juvenile herring to adults during the spawn season, and that the phenomenon may be regionally dependent. This lends 

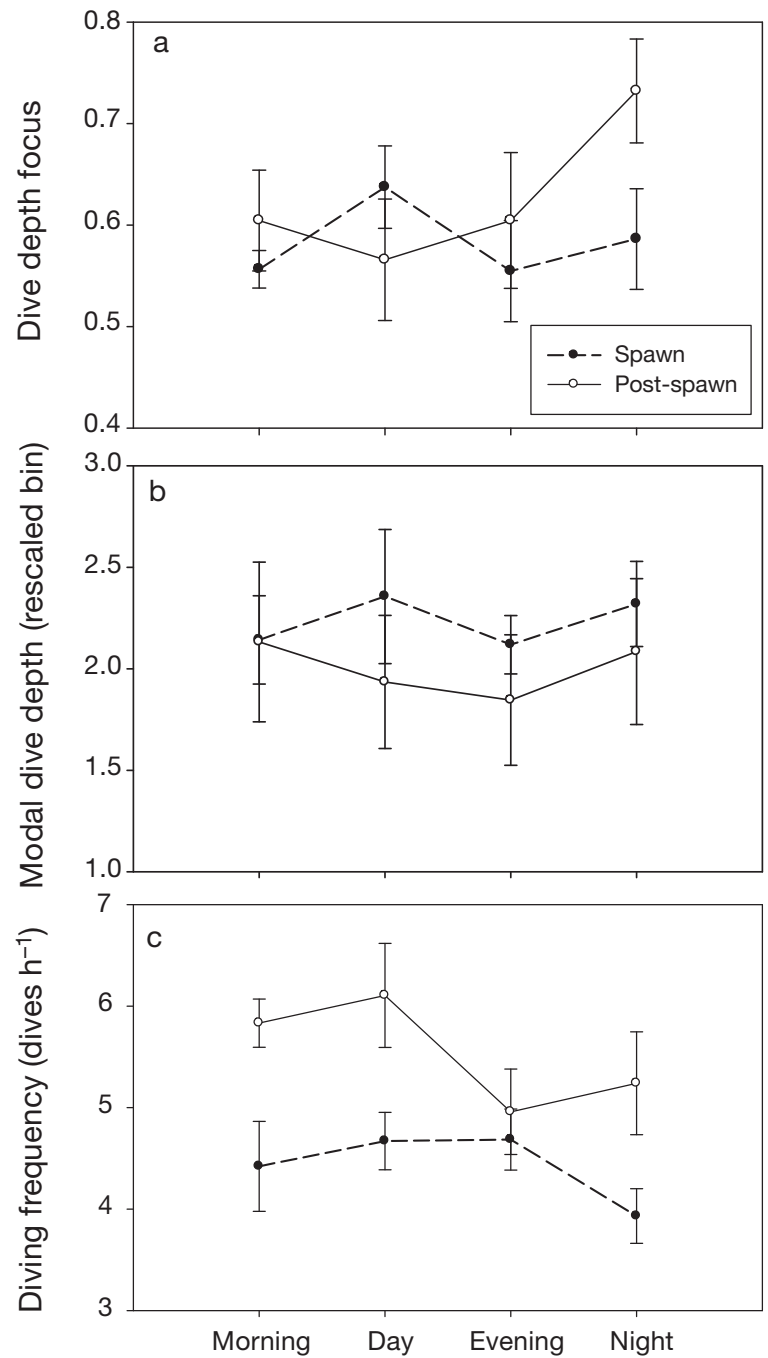

Fig. 4. Relationship between LME model factors (period, season) and each diving variable: (a) dive depth focus, (b) modal dive depth, and (c) diving frequency. Periods: morning (04:00-09:59 h), day (10:00-15:59 h), evening (16:0021:59 h), and night (22:00-03:59 h). Seasons: (•) spawn, (o) post-spawn. Circles and error bars indicate mean \pm SE

further support to the explanation that foraging on adult herring is likely more profitable for Protection Island seals during the post-spawn season when herring energy density is highest.

\section{Seal foraging areas}

Based on the UDOI index, 2 of the 5 harbor seals from Protection Island showed very high foraging site fidelity between seasons (Table 2). Of the seals that did use different foraging areas between seasons, only one appeared to forage in a noticeably different region within the Strait of Juan de Fuca (Fig. 3, seal F1). These results are somewhat counter to our prediction that harbor seals use different foraging areas when herring are spawning versus when they are not spawning. While harbor seals have the ability to make long distance movements, in some cases exceeding $500 \mathrm{~km}$, we did not observe any such major displacements (Lowry et al. 2001). In this case we primarily observed only minor differences in the foraging areas used by harbor seals between seasons, consistent with the findings of researchers who have detected high foraging area fidelity in harbor seals (Suryan \& Harvey 1998, Tollit et al. 1998).

Also contrary to our predictions, harbor seal use of documented herring holding areas was greater during the season when herring do not spawn, and the overall use of the spawning areas was minimal (Table 3). While there is some spatial variability in the documented herring holding areas, the fact that harbor seals consistently used the holding areas more in the post-spawn season suggests that portions of herring spawning habitat are important foraging areas for harbor seals regardless of the presence of adult herring. It also indicates that the presence of adult herring in holding areas does not cause harbor seals to increase their use of those areas.

The only 2 herring areas that overlapped with harbor seal foraging areas were those closest to the haul-out site. While all of the inshore herring spawning areas are within the foraging range of harbor seals on Protection Island, none of the distant spawning areas were used by tagged seals. If Strait of Juan de Fuca herring populations were indeed insufficient to elicit a response from Protection Island harbor seals, it is noteworthy that seals did not change their foraging areas to reach other locations of high spawning herring abundance within their range. This implies that harbor seals on Protection Island were either unaware of the availability of the other spawning aggregations, or foraging on those aggregations was not profitable enough to elicit an aggregative response from distant harbor seals. Our data suggest that despite their high mobility and therefore high likelihood of exhibiting a numeric response to prey pulses (Rose \& Polis 1998, Ostfeld \& Keesing 2000), harbor seals did not appear to alter their foraging areas to utilize seasonal pulses of spawning herring.

\section{Seal diving behavior}

Harbor seal diving behavior was in general very focused, but there was high individual variability in 
the depth bins used between seals (Fig. 4). The average values of harbor seal dive depth focus were $>0.5$ in both seasons, regardless of time of day, indicating that for all dive histograms the majority of dives in a 6 -h period were within a single depth bin. However, most of variability in modal dive depth was explained by seal-to-seal variation, suggesting that the depth ranges used differed between animals (Table 4). We also detected strong seasonal and diurnal variations in harbor seal diving focus and frequency during the study period (Fig. 4a, c). In the herring spawn season, harbor seal dive depth focus peaked during the day, and diving was overall less frequent during this period. These results are consistent with our prediction that harbor seal diving behavior during the spawn season would reflect the distribution of diurnally migrating prey. However, during the spawn season harbor seals primarily consumed Walleye pollock and juvenile herring, rather than consuming adult herring as we had expected (Fig. 2). Pollock of the size class eaten by harbor seals and juvenile herring both occupy nearshore waters and perform daily vertical migrations; during the day they form dense shoals near the seafloor, and then disperse into the upper water column at night to feed (Lowry et al. 1988, Gustafson et al. 2000). The peak in daytime dive depth focus during the spawn season suggests that seals adopted a benthic or demersal foraging strategy, likely targeting dense schools of young herring and pollock. However, we did not observe a corresponding pattern in harbor seal dive depths that would support that conclusion. This may be due to the highly variable bathymetry in the study region and the large individual variability in harbor seal foraging areas (Suryan \& Harvey 1998, Hardee 2008). In fact, the inclusion of diving focus as a factor in pinniped studies that incorporate binned dive data was partially driven by the goal of detecting benthic foraging in habitats with highly variable bathymetry (Frost et al. 2001). Given the bathymetric complexity of the habitat surrounding Protection Island, it is not surprising that we did not detect a consistent pattern of depths used across all seals.

The most striking difference in diving behavior between seasons was the large peak in nighttime diving focus during the post-spawn season (Fig. 4a), accompanied by an increase in overall diving effort (Fig. 4c). During that season we also observed a decrease in the importance of pollock in seal diet and an increase in sand lance consumption. The peak in nighttime diving focus is likely related to the ob- served increase in foraging on sand lance during the post-spawn season. Sand lance bury themselves in the seafloor and remain dormant throughout most of the winter until food availability increases the following spring. Once active, sand lance forage in large schools during the day and migrate nightly into the substrate to avoid predation (Robards et al. 2000). Harbor seals regularly forage on buried sand lance by disturbing them out of the sediment, and it has been demonstrated that this benthic foraging strategy is more profitable for seals than pursuing daytime schools of sand lance (Bowen et al. 2002). The peak in harbor seal diving focus during the postspawn season therefore may be due to an increase in nighttime benthic foraging on sand lance during that season.

Given the differences in harbor seal diet between seasons, the overall decrease in harbor seal diving effort during the spawn season is more difficult to interpret. We expected that seal diving frequency would be lower during the spawn season because less effort would be required to meet energetic needs when foraging on densely aggregated adult herring. However, while we did observe lower diving effort during the spawn season, we also found that seals did not consume many adult herring at that time (Fig. 2). One possible explanation for the reduction in diving effort during the spawn season is that juvenile herring and pollock require less handling time than adults, and thus multiple prey could be acquired within a single dive. In that case, fewer dives may actually be required for harbor seals to meet their energetic needs when foraging on juvenile fish. The subsequent increase in diving frequency during the post-spawn season could reflect the greater effort required to catch adult herring and other energy-rich prey e.g. salmonids, available during that season. However, that increase in foraging effort during the post-spawn season is likely offset by the high energy density of their prey at that time. These findings clearly demonstrate the usefulness of concurrent diet analysis when interpreting pinniped telemetry data, and emphasize the importance of a multi-metric approach to understanding predator responses to changes in prey availability.

\section{CONCLUSIONS}

Protection Island harbor seals exhibited several behavioral differences between the spawn and postspawn seasons. First and foremost, harbor seals consumed primarily juvenile herring and pollock in the 
spawn season, and then switched to adult herring and sand lance in the post-spawn season. Harbor seal diving behavior was generally highly focused and peaked at night during the post-spawn season, concurrent with an increase in overall diving effort (i.e. frequency). Herring holding areas were used by harbor seals more during the season when herring do not spawn, and seal use was limited to those areas closest to the haul-out site. Overlap indices indicated that 3 of the 5 tagged seals changed their foraging utilization distributions between seasons; however only one seal used a largely different foraging area during the spawn season.

Pacific herring spawning aggregations are an important seasonal resource pulse for a wide variety of consumers including pinnipeds (Hourston \& Haegele 1980, Lassuy 1989, Willson \& Womble 2006, Therriault et al. 2009). However, despite suggestive evidence that harbor seals are likely to utilize these seasonal aggregations, our data did not indicate that spawning herring are important prey for Protection Island harbor seals. Instead we found that juvenile herring and Walleye pollock were the key prey species for harbor seals during the season when herring are spawning. While this study was limited by a small number of tagged seals and a single scat collection per season, our findings are consistent with a review paper that did not detect a response by harbor seals to spawning herring aggregations (Willson \& Womble 2006). They are also consistent with previous harbor seal diet observations in the northern Strait of Juan de Fuca that indicated high levels of juvenile herring consumption in the region (Olesiuk et al. 1990). Our findings may be partially explained by a reduction in herring spawner biomass in the Strait of Juan de Fuca; however there is much stronger evidence that adult herring are less profitable for harbor seals during the spawn season than they are during other seasons.

This study indicates that the response of predators to resource pulses is influenced not only by the magnitude of the pulse but also by seasonal changes in prey energy density, prey handling time, and the availability of alternative prey. These observations highlight the ecological complexity of the consumer response to changes in prey availability, and may also explain why consumers sometimes do not respond as predicted to resource pulses. A similar study design to this one that incorporates a concurrent survey of prey availability between seasons could yield substantial additional insight into the relationship between harbor seals and their herring prey.
Acknowledgements. We thank J. Schweigert and D. Hay for the use of their herring survey data, J. Fieberg for assistance in data analysis, and L. Yang, A. Trites, P. Olesiuk, and K. Stick for their conceptual feedback. Field support was provided by the Washington Department of Fish and Wildlife (WDFW) pinniped capture team, graduate and undergraduate students of the Western Washington University (WWU) Marine Behavior and Ecology lab, and National Marine Fisheries Service technicians. Many thanks to J. Fieberg, P. Olesiuk, and anonymous referees for their helpful feedback on manuscript drafts. Funding for this project was provided by the National Science Foundation (Award \#0550443) to A.A.-G. Financial support for A.C.T. came from the WWU Ross Graduate Tuition Scholarship, WWU Biology Alumni Scholarship, and the WWU Research and Sponsored Programs Fund for the Enhancement of Graduate Research. All animal captures were performed under Marine Mammal Protection Act Permit No. 782-1702-05.

\section{LITERATURE CITED}

Adams NG, Lesoing M, Trainer VL (2000) Environmental conditions associated with domic acid in razor clams on the Washington coast. J Shellfish Res 19:1007-1015

Akaike H (1974) A new look at the statistical model identification. IEEE Trans Automat Contr 19:716-723

Andersen SM, Teilmann J, Harders PB, Hansen EH, Hjøllund D (2007) Diet of harbour seals and great cormorants in Limfjord, Denmark: interspecific competition and interaction with fishery. ICES J Mar Sci 64:1235-1245

Anderson EM, Lovvorn JR, Esler D, Boyd WS, Stick KC (2009) Using predator distributions, diet, and condition to evaluate seasonal foraging sites: sea ducks and herring spawn. Mar Ecol Prog Ser 386:287-302

Austin D, McMillan JI, Bowen WD (2003) A three-stage algorithm for filtering erroneous Argos satellite locations. Mar Mamm Sci 19:371-383

Bates D, Maechler M (2009) lme4: linear mixed-effects models using S4 classes. R package version 0.999375-32

Bologna PAX, Fetzer ML, McDonnell S, Moody EM (2005) Assessing the potential benthic-pelagic coupling in episodic blue mussel (Mytilus edulis) settlement events within eelgrass (Zostera marina) communities. J Exp Mar Biol Ecol 316:117-131

Bowen WD, Tully D, Boness DJ, Bulheier BM, Marshall GJ (2002) Prey-dependent foraging tactics and prey profitability in a marine mammal. Mar Ecol Prog Ser 244: 235-245

Calenge C (2006) The package 'adehabitat' for the R software: a tool for the analysis of space and habitat use by animals. Ecol Model 197:516-519

Cannon D (ed) (1987) Marine fish osteology: a manual for archaeologists. Publication 18, Archaeology Press, Simon Fraser University, Burnaby, BC

Clarke M (1986) A handbook for the identification of cephalopod beaks. Oxford University Press, Oxford

> Coyne MS, Godley BJ (2005) Satellite Tracking and Analysis Tool (STAT): an integrated system for archiving, analyzing, and mapping animal tracking data. Mar Ecol Prog Ser 301:1-7

Everitt RD, Gearin PJ, Skidmore JS, DeLong RL (1981) Prey items of harbor seals and California sea lions in Puget Sound, Washington. The Murrelet 62:83-86

> Fieberg J, Kochanny CO (2005) Quantifying home-range 
overalp: the importance of the utilization distribution. J Wildl Manag 69:1346-1359

Frost KJ, Simpkins MA, Lowry LF (2001) Diving behavior of subadult and adult harbor seals in Prince William Sound, Alaska. Mar Mamm Sci 17:813-834

Getz WM, Fortmann-Roe S, Cross PC, Lyons AJ, Ryan SJ, Wilmers CC (2007) LoCoH: nonparametric kernel methods for constructing home ranges and utilization distributions. PLoS ONE 2:e207

Grigg EK, Klimley AP, Allen SG, Green DE, Elliott-Fisk DL, Markowitz H (2009) Spatial and seasonal relationships between Pacific harbor seals (Phoca vitulina richardii) and their prey, at multiple scales. Fish Bull 107:359-372

Gustafson R, Lenarz W, McCain B, Schmitt C, Grant W, Builder T, Methot RD (2000) Status review of Pacific hake, Pacific cod, and Walleye pollock from Puget Sound, Washington. NOAA Tech Memo NMFS-NWFSC-44

Gustafson R, Drake J, Ford M, Myers J, Holmes E, Waples R (2006) Status Review of Cherry Point Pacific herring (Clupea pallasii) and updated status review of the Georgia Basin Pacific herring distinct population segment under the Endangered Species Act. NOAA Tech Memo NMFS-NWFSC-76

Haegele CW, Schweigert JF (1985) Distribution and characteristics of herring spawning grounds and description of spawning behavior. Can J Fish Aquat Sci 42:s39-s55

Hardee S (2008) Movements and home ranges of harbor seals (Phoca vitulina) in the inland waters of the Pacific Northwest. MSc thesis, Western Washington University, Belligham, WA

Harvey J (1989) Assessment of errors associated with harbour seal (Phoca vitulina) faecal sampling. J Zool 219: $101-111$

Harvey JT, Loughlin TR, Perez MA, Oxman DS (2000) Relationship between fish size and otolith length for 63 species of fishes from the eastern North Pacific Ocean. NOAA Tech Rep NMFS 150

- Hastings KK, Frost KJ, Simpkins MA, Pendleton GW, Swain UG, Small RJ (2004) Regional differences in diving behavior of harbor seals in the Gulf of Alaska. Can J Zool 82:1755-1773

> Hay DE (1985) Reproductive biology of Pacific herring (Clupea harengus pallasii). Can J Fish Aquat Sci 42(Suppl 1): s111-s126

> Helfield JM, Naiman RJ (2001) Effects of salmon-derived nitrogen on riparian forest growth and implications for stream productivity. Ecology 82:2403-2409

Holt RD (2008) Theoretical perspectives on resource pulses. Ecology 89:671-681

Hourston AS, Haegele CW (1980) Herring on Canada's Pacific coast. Can Spec Publ Fish Aquat Sci 48

- Huber HR, Jeffries SJ, Brown RF, DeLong RL, Van Blaricom G (2001) Correcting aerial survey counts of harbor seals (Phoca vitulina richardsi) in Washington and Oregon. Mar Mamm Sci 17:276-293

> Huck M, Davidson J, Roper TJ (2008) Comparison of two sampling protocols and four home-range estimators using radio-tracking data from urban badgers Meles meles. Wildl Biol 14:467-477

- Hyrenbach KD (2002) Oceanographic habitats of two sympatric North Pacific albatrosses during the breeding season. Mar Ecol Prog Ser 233:283-301

Jeffries S, Brown R, Harvey J (1993) Techniques for capturing, handling and marking harbor seals. Aquat Mamm 19:21-25
Jeffries SJ, Gearin PJ, Huber HR, Saul DL, Pruett DA (2000) Atlas of seal and sea lion haulout sites in Washington. Washington Department of Fish and Wildlife, Olympia, WA

Kashiwada J, Recksiek CW, Karpov KA (1979) Beaks of the market squid, Loligo opalescens, as tools for predator studies. CCOFI Rep XX:65-69

Lance MM, Jeffries SJ (2007) Temporal and spatial variability of harbor seal diet in the San Juan Island archipelago. Washington Department of Fish and Wildlife, Olympia, WA

Lance MM, Orr AJ, Riemer SD, Weise MJ, Laake JL (2001) Pinniped food habits and prey identification techniques protocol. AFSC Processed Rep 2001-04, Alaska Fish Sci Cent, Natl Mar Fish Serv, NOAA, Seattle, WA

Lassuy DR (1989) Species profiles: Life histories and environmental requirements of coastal fishes and invertebrates (Pacific northwest)-Pacific herring. US Fish Wildl Serv Biol Rep 82(11.126)

Lesage V, Hammill MO, Kovacs KM (1999) Functional classification of harbor seal (Phoca vitulina) dives using depth profiles, swimming velocity, and an index of foraging success. Can J Zool 77:74-87

Longhurst A (2001) A major seasonal phytoplankton bloom in the Madagascar Basin. Deep-Sea Res I 48:2413-2422

Lowry LF, Frost KJ, Loughlin TR (1988) Importance of walleye pollock in the diets of marine mammals in the Gulf of Alaska and Bering Sea, and implications for fishery management. Proc Int Symp Biol Manag Walleye Pollock, Anchorage, AK, p 701-726

Lowry LF, Frost KJ, Ver Hoef JM, DeLong RL (2001) Movements of satellite-tagged subadult and adult harbor seals in Prince William Sound, Alaska. Mar Mamm Sci 17: 835-861

Luque SP (2007) Diving behaviour analysis in R. R News 7: $8-14$

Luxa K (2008) Food habits of harbor seals (Phoca vitulina) in two estuaries in northern Puget Sound, Washington. MSc thesis, Western Washington University, Bellingham, WA

Morrow JE (1979) Preliminary keys to the otoliths of some adult fishes of the Gulf of Alaska, Bering Sea, and Beaufort Sea. NOAA Circular Rep 420

> Naiman RJ, Bilby RE, Schindler DE, Helfield JM (2002) Pacific salmon, nutrients, and the dynamics of freshwater and riparian ecosystems. Ecosystems 5:399-417

Norcross BL, Brown ED, Foy RJ, Frandsen M and others (2001) A synthesis of the life history and ecology of juvenile Pacific herring in Prince Willian Sound, Alaska. Fish Oceanogr 10(Suppl. 1):42-57

Nowlin WH, Vanni MJ, Yang LH (2008) Comparing resource pulses in aquatic and terrestrial ecosystems. Ecology 89:647-659

Olesiuk PF (1993) Annual prey consumption by harbour seals (Phoca vitulina) in the Strait of Georgia, British Columbia. Fish Bull 91:491-515

Olesiuk PF, Bigg MA, Ellis GM, Crockford SJ, Wigen RJ (1990) An assessment of the feeding habits of harbour seals (Phoca vitulina) in the Strait of Georgia, British Columbia, based on scat analysis. Can Tech Rep Fish Aquat Sci 1730

> Ostfeld RS (1986) Territoriality and mating system of California voles. J Anim Ecol 55:691-706

> Ostfeld RS, Keesing F (2000) Pulsed resources and community dynamics of consumers in terrestrial ecosystems. Trends Ecol Evol 15:232-237 
Paul AJ, Paul JM, Brown ED (1998) Fall and spring somatic energy content for Alaskan Pacific herring (Clupea pallasi Valenciennes 1847) relative to age, size and sex. J Exp Mar Biol Ecol 223:133-142

Penttila D (2007) Marine forage fishes in Puget Sound. Puget Sound Nearshore Partnership Technical Report 2007-03, Seattle District, US Army Corps of Engineers, Seattle, WA

Phillips EM, Harvey JT (2009) A captive feeding study with the Pacific harbor seal (Phoca vitulina richardii): implications for scat analysis. Mar Mamm Sci 25:373-391

Powell RA, Boitani L, Fuller T (2000) Animal home ranges and territories and home range estimators. In: Boitani L, Fuller TK (eds) Research techniques in animal ecology: controversies and consequences. Columbia University Press, New York, NY, p 65-110

Robards M, Willson M, Armstrong R, Piatt J (eds) (2000) Sand lance: a review of biology and predator relations and annotated bibliography. Research Paper PNW-RP521, US Department of Agriculture, Forest Service, Portland, OR

Rose MD, Polis GA (1998) The distribution and abundance of coyotes: the effects of allochthonous food subsidies from the sea. Ecology 79:998-1007

Scharf FS, Juanes F, Rountree RA (2000) Predator size-prey size relationships of marine fish predators: interspecific variation and effects of ontogeny and body size on trophic-niche breadth. Mar Ecol Prog Ser 208:229-248

Schweigert J, Christensen LB, Haist V (2009) Stock assessments for British Columbia herring in 2008 and forecasts of the potential catch in 2009. Canadian Science Advisory Secretariat 2009/019

Stick KC (2005) 2004 Washington State herring stock status report. SS 05-01, Washington Department of Fish and Wildlife, Olympia, WA

Stick KC, Lindquist A (2009) 2008 Washington State herring stock status report. SS 09-01, Washington Department of Fish and Wildlife, Olympia, WA

Suryan RM, Har vey JT (1998) Tracking harbor seals (Phoca vitulina richardsi) to determine dive behavior, foraging activity, and haul-out site use. Mar Mamm Sci 14: 361-372

Therriault TW, Hay DE, Schweigert JF (2009) Biological overview and trends in pelagic forage fish abundance in the Salish Sea (Strait of Georgia, British Columbia). Mar Ornithol 37:3-8

Thompson PM, Pierce GJ, Hislop JRG, Miller D, Diack JSW

Editorial responsibility: Michael Castellini,

Fairbanks, Alaska, USA
(1991) Winter foraging by common seals (Phoca vitulina) in relation to food availability in the inner Moray Firth, N.E. Scotland. J Anim Ecol 60:283-294

- Thompson PM, Mackay A, Tollit DJ, Enderby S, Hammond PS (1998) The influence of body size and sex on the characteristics of harbour seal foraging trips. Can J Zool 76: 1044-1053

Tollit DJ, Black AD, Thompson PM, Mackay A and others (1998) Variations in harbour seal (Phoca vitulina) diet and dive-depths in relation to foraging habitat. J Zool (Lond) 244:209-222

Tollit D, Heaslip SG, Joy R, Call KA, Trites AW (2004) A method to improve size estimates of Walleye pollock (Theragra chalcogramma) and Atka mackerel (Pleurogrammus monopterygius) consumed by pinnipeds: digestion correction factors applied to bones and otoliths recovered in scats. Fish Bull 102:498-508

> Trites AW, Joy R (2005) Dietary analysis from fecal samples: How many scats are enough? J Mammal 86:704-712

Williams TM, Kooyman GL (1985) Swimming performance and hydrodynamic characteristics of harbor seals Phoca vitulina. Physiol Zool 58:576-589

> Willson MF, Halupka KC (1995) Anadromous fish as a keystone species in vertebrate communities. Conserv Biol 9: 489-497

Willson MF, Womble JN (2006) Vertebrate exploitation of pulsed marine prey: a review and the example of spawning herring. Rev Fish Biol Fish 16:183-200

Wolff G (1982) A beak key for eight eastern tropical Pacific cephalopod species with relationships between their beak dimensions and size. Fish Bull 26:357-370

Womble JN, Sigler MF (2006) Seasonal availability of abundant, energy-rich prey influences the abundance and diet of a marine predator, the Steller sea lion Eumetopias jubatus. Mar Ecol Prog Ser 325:281-293

Worton BJ (1995) Using Monte Carlo simulation to evaluate kernel-based home range estimators. J Wildl Manag 59: 794-800

Wright BE (2010) Use of chi-square tests to analyze scatderived diet composition data. Mar Mamm Sci 26: 395-401

Yang LH, Bastow JL, Spence KO, Wright AN (2008) What can we learn from resource pulses? Ecology 89:621-634

Yang LH, Edwards KF, Byrnes EJ, Bastow JL, Wright AN, Spence KO (2010) A meta-analysis of resource pulseconsumer interactions. Ecol Monogr 80:125-151

Submitted: January 26, 2011; Accepted: August 26, 2011

Proofs received from author(s): October 31, 2011 